\title{
Major Advances in Nutrition: Impact on Milk Composition
}

\author{
T. C. Jenkins ${ }^{\star 1}$ and M. A. McGuire† \\ *Department of Animal and Veterinary Sciences, Clemson University, Clemson, SC, 29634 \\ †Department of Animal and Veterinary Science, University of Idaho, Moscow 83844
}

\section{ABSTRACT}

A number of major scientific advances have been realized in the last $25 \mathrm{yr}$ in determining the opportunities and limitations of altering milk composition through nutritional manipulation. Because of the greater sensitivity of milk fat to dietary manipulation than either protein or lactose, nutritional control of milk fat content and fatty acid composition received a great deal of attention. New information emerged linking ruminal production of trans fatty acid isomers with milk fat depression. As a result, research on fatty acid biohydrogenation intensified yielding new insight on the origin of specific trans fatty acid isomers originating from ruminal biohydrogenation and how these isomers were modified by the action of mammary enzymes. The discovery of conjugated linoleic acid (CLA) as a potent anticarcinogen also led to extensive work on enhancing its concentration in milk through nutritional manipulation and discovering the physiological effects of specific CLA isomers. New protected fats were developed in recent years that were designed to resist biohydrogenation and enhance the concentration of unsaturated fatty acids in milk. The nutritional factors receiving the most attention during the last $25 \mathrm{yr}$ for their influence on milk protein content were forage-to-concentrate ratio, the amount and source of dietary protein, and the amount and source of dietary fat. New insights were tested on modes of action whereby fat supplements caused a decline in protein concentration. Changes in milk lactose concentration occur only in extreme and unusual feeding situations, but the basic biology of lactose synthesis and regulation are still being explored using modern molecular techniques. This paper highlights the major advances in controlling milk composition by dietary manipulation and how it influences the entire animal system from practical feeding studies to basic cellular work on mammary tissue metabolism.

Key words: milk, composition, dairy, nutrition

Received September 6, 2004.

Accepted March 22, 2005.

${ }^{1}$ Corresponding author: tjnkns@Clemson.edu.

\section{INTRODUCTION}

The interest and momentum in manipulating the composition of milk that was evident at the 75th anniversary of the American Dairy Science Association has carried forward to the present day centennial anniversary. The basic driving forces for manipulating the composition of milk remain the same, and include 1) improving the manufacturing and processing of milk and dairy products, 2) altering the nutritional value of milk to conform to dietary guidelines set forth by governmental agencies, and 3) using milk as a delivery system for nutraceuticals with known benefits to human health.

There was a clear realization in the early 1980s that dietary control of milk composition had its opportunities but also its restrictions. The most sensitive component of milk to dietary manipulation was fat content, which could be changed over a range of 3 percentage units. It was clear that lactose content could not be manipulated by dietary changes, except under extreme and unusual feeding situations. Milk protein was more responsive to diet (over a 0.5-percentage unit range) than lactose, but less responsive than fat. The period from 1980 to 2005 has seen efforts at trying to alter the content or composition of all 3 components. As expected, the greatest changes were made in milk fat and fatty acid composition.

This paper will review the major scientific advances in manipulation of milk composition over the last 25 yr. A multitude of factors influence the final composition of milk including genetics and breed of animal, environment, stage of lactation, parity, and nutrition of the cow. Although all of these factors work in combination to determine the final composition of milk, the focus of this paper is on nutrition of the cow and how it influences milk fat, protein, and lactose. In the case of nutritional control, a change in milk composition is realized when one or more desired nutrients are incorporated into the diet of the cow, followed by absorption and transport of the nutrient to the mammary gland, and terminates with secretion of the nutrient in milk as either a desired component or as a regulator of milk synthesis.

Manipulation of each milk component is discussed separately with emphasis on the changes desired, the 
Table 1. Nutrient composition of whole and whole, dry milk ${ }^{1}$

\begin{tabular}{lcc}
\hline & Whole & $\begin{array}{c}\text { Whole, } \\
\text { dry }\end{array}$ \\
\hline Water, \% & 88.32 & 2.47 \\
Protein, \% & 3.22 & 26.32 \\
Fat, \% & 3.25 & 26.71 \\
Ash, \% & 0.69 & 6.08 \\
Carbohydrate, \% (by difference) & 4.52 & 38.42 \\
Energy, kcal/100 g & 60 & 496 \\
Cholesterol, mg/100 g & 10 & 97 \\
Fatty acids, \% of total & & \\
Total saturated & 64.9 & 66.1 \\
Total monounsaturated & 28.3 & 31.3 \\
Total polyunsaturated & 6.8 & 2.6 \\
\hline
\end{tabular}

${ }^{1}$ Taken from USDA National Nutrient Database for Standard Reference, Release 18 (2004).

advances in enhancing the absorption and delivery of the desired nutrient to the mammary gland, and use of the nutrient by the mammary tissue to achieve the desired objective. The ability to control milk composition by dietary manipulation came from significant scientific contributions of the entire animal system, from practical studies on feeding systems to basic cellular work on mammary tissue metabolism.

\section{MILK FAT}

\section{Target}

Interest in manipulating the fat content of milk was in full force entering the 1980s. The Dietary Guidelines for Americans published in 1980 by the US Department of Health and Human Services and the Department of Agriculture (USDA) emphasized reductions in total fat, saturated fat, and cholesterol. Similar recommendations for Americans were made in subsequent reports published every $5 \mathrm{yr}$ up to and including the latest report in 2000, and were also made for Europeans by the Department of Health (1994) in the United Kingdom. These publications usually identified animal products as the main source of saturated fat and cholesterol.

Whole milk is over 96\% fat-free, but on a dry basis, fat content is high (27\%) with the majority (65\%) of the fatty acids being saturated (Table 1). About $50 \%$ of the calories in milk come from fat. In 1994, dairy products accounted for $9.3 \%$ of the total food energy consumed, $12.3 \%$ of the fat consumed, and $23.6 \%$ of the saturated fat consumed in the United States (Economic Research Service/USDA). Milk and milk products in the United Kingdom in 1992 accounted for $15 \%$ of the total fat consumed and $23 \%$ of the saturated fat consumed.

The pressure to reduce total fat content of dairy products, as well as to reduce its saturation, has continued throughout the 1980s and 1990s and into the current year. Producers were generally in conflict with consum- ers over milk fat content. In most of the United States, the pricing system for milk offered producers a premium for high fat content, whereas many consumers were focused on low-fat dairy products that conformed to dietary guidelines. The dilemma was solved through postharvest manipulation of fat content. Blending at the processing plant has allowed consumers to choose among fluid milk products that range from skim to whole milk, including 1 and $2 \%$ fat choices. Americans on a per capita basis were consuming less than $30 \mathrm{~L}$ of whole milk in 2001 compared with $95 \mathrm{~L}$ in 1970 . In contrast, consumption of lower fat milks increased from 23 to $57 \mathrm{~L}$ per person from 1970 to 2001.

Nutritional control of milk fatty acid profile has received considerable attention over the last $25 \mathrm{yr}$. Whether the goal is to improve manufacturing properties of milk or to enhance the concentration of fatty acids having beneficial health effects in humans, the key objective was usually to increase one or more unsaturated fatty acids in milk. For instance, increasing oleic acid content in milk enhances the plasticity and softness of milk fat, which has interested processors attempting to improve the spreadability of butter. Moreover, market pressures continued over the last $25 \mathrm{yr}$ to find avenues for enhancing the concentration of the "healthy" unsaturated fatty acids in milk. As an example, the Wisconsin Milk Marketing Board in 1988 published recommendations of a Milk Fat Roundtable stating that an "ideal" milk would contain no more than $8 \%$ saturated fatty acids, less than $10 \%$ polyunsaturated fatty acids, and the remainder ( $82 \%)$ as monounsaturated fatty acids. In addition, information emerged about the health effects of unsaturated trans fatty acids produced in the rumen, which led to interest in enhancing their concentration in meat and milk.

Research then followed to determine the ability of different diet formulations to reduce milk fat content or enhance the concentration of unsaturated fatty acids. Dietary factors receiving the most attention were the amounts of grain and fat fed to cows. Each of these will be discussed separately, with a greater emphasis on the more researched fat supplements. The control of milk fat and fatty acid composition by fat supplements is complex because the transfer of dietary unsaturated fatty acids to milk can be significantly lessened by several factors including their destruction by ruminal microorganisms, poor rates of intestinal absorption, and their deposition in adipose tissue rather than in mammary fat. Thus, major advances in using fat supplements to alter milk fatty acid profile included significant work in understanding and controlling fatty acid destruction by ruminal microorganisms and the uptake and use of unsaturated fatty acids by the mammary gland. 


\section{Grain Feeding}

Cereal grains are used liberally in dairy rations in the United States because they are a cost-effective source of digestible energy needed for maintaining high levels of milk production. In addition to stimulating milk yield, higher grain intakes also depress milk fat percentage and alter fatty acid composition. Grain feeding typically reduces the proportions of milk fatty acids having 6 to 16 carbons, and increases the proportion of 18-carbon unsaturated fatty acids. Several theories to explain the cause for the grain-induced milk fat depression were under scrutiny in the early $1980 \mathrm{~s}$, but the exact cause was not clear. Two theories receiving most of the attention at the time were 1) inadequate rumen production of acetate and butyrate to support milk fat synthesis, and 2) propionate from grain stimulates circulating insulin concentration, which redirects metabolites away from mammary tissue. Multiple studies have shown that either theory is unlikely. See Bauman and Griinari (2003) for a recent and thorough account of the theories for milk fat depression.

One of the major breakthroughs on the theories of milk fat depression in the last $25 \mathrm{yr}$ was the refocus on trans fatty acids as the causative agent of milk fat depression in dairy cattle. Although trans fatty acids were implicated in milk fat depression many years earlier, it was new studies done in the early 1990s by Richard Erdman (dairy cattle) and Beverly Teter (rat studies) at The University of Maryland that redirected attention to trans fatty acids. Studies were done at several locations showing an inverse relationship between trans fatty acids in milk and milk fat content. Several reports indicated substantial increases in milk trans fatty acids without reductions in milk fat content, which raised questions that not all trans fatty acid isomers were associated with milk fat depression. Later work showed that milk fat depression was more closely associated with the production of trans-10 fatty acid isomers in the rumen than with trans isomers in general. Grain feeding was shown to enhance the production of the trans-10 fatty acid isomers by ruminal microorganisms. An important study done at Cornell University by Dale Bauman and colleagues demonstrated severe milk fat depression in cows infused with trans10,cis-12 conjugated linoleic acid (CLA), but no depression following infusion of the cis-9, trans-11 CLA isomer. Further work with other conjugated dienes and trienes have failed to find any further inhibitor of milk fat synthesis. Thus, it appears that trans-10,cis-12 CLA is the most likely factor in milk fat depression.

\section{Fat Supplements}

Extensive work on feeding fat to dairy cattle occurred during the last $25 \mathrm{yr}$. The emphasis in the early 1980s was on using fat to provide more energy for milk production. During this time period, extensive work was done on developing rumen-inert or bypass fats that minimized digestibility problems that often occurred when feeding unsaturated oils to dairy cows. This led to commercial development of a variety of bypass fats, including calcium salts of fatty acids and products enriched in saturated fatty acids. Analysis of milk fatty acid composition was usually done in the same studies providing a large databank of information on the extent that fat supplements could alter milk fatty acid composition.

Biohydrogenation. Untreated vegetable oils high in unsaturated fatty acids have only limited ability to alter milk fatty acid composition. The reason for this was established decades before the 1980s, and is attributed to the microbial population located mainly in the rumen that transform dietary unsaturated fatty acids. Therefore, delivery of unsaturated fatty acids to mammary tissue is limited even when their dietary concentration is high. The ruminal microorganisms transform unsaturated fatty acids in a process called biohydrogenation, in which hydrogen addition via microbial enzymes removes double bonds in a fatty acyl chain converting it from unsaturated to saturated (Figure 1).

There has been considerable interest over the last 25 $\mathrm{yr}$ in finding ways to shield dietary unsaturated fatty acids from biohydrogenation to enhance their absorption and delivery to the mammary gland. One of the first successful rumen-protected fats was prepared by embedding unsaturated oils within a protein shell made resistant to microbial attack by cross-linking with formaldehyde. The formaldehyde-protected fats were developed in Australia in the early 1970s and had dramatic effects on enhancing unsaturated fatty acid in milk. Although the formaldehyde-treated fats received attention in other countries, the technology was not adopted commercially in the United States. Possible reasons include health concerns about the use of formaldehyde, cost and distribution of the product, or inconsistencies in level of rumen protection.

Research to find alternative rumen-protected fats continued throughout the past 25 yr. Figures 2 and 3 show examples of changes in oleic and linoleic acid concentrations in milk fat when various forms of rumen-protected fats were fed to dairy cows. Oleic acid concentration in milk fat varied from 18 to $24 \%$ of total fatty acids when control rations containing no added fat were fed to cows. When rumen-protected fats were fed to cows, oleic acid in milk varied from 18 to as much as $48 \%$. The effects of fat source on milk linoleic acid concentration were less dramatic. Linoleic acid concentration in milk normally ranges from 1.5 to as much as $4 \%$ when cows are fed control diets with no added fat. 


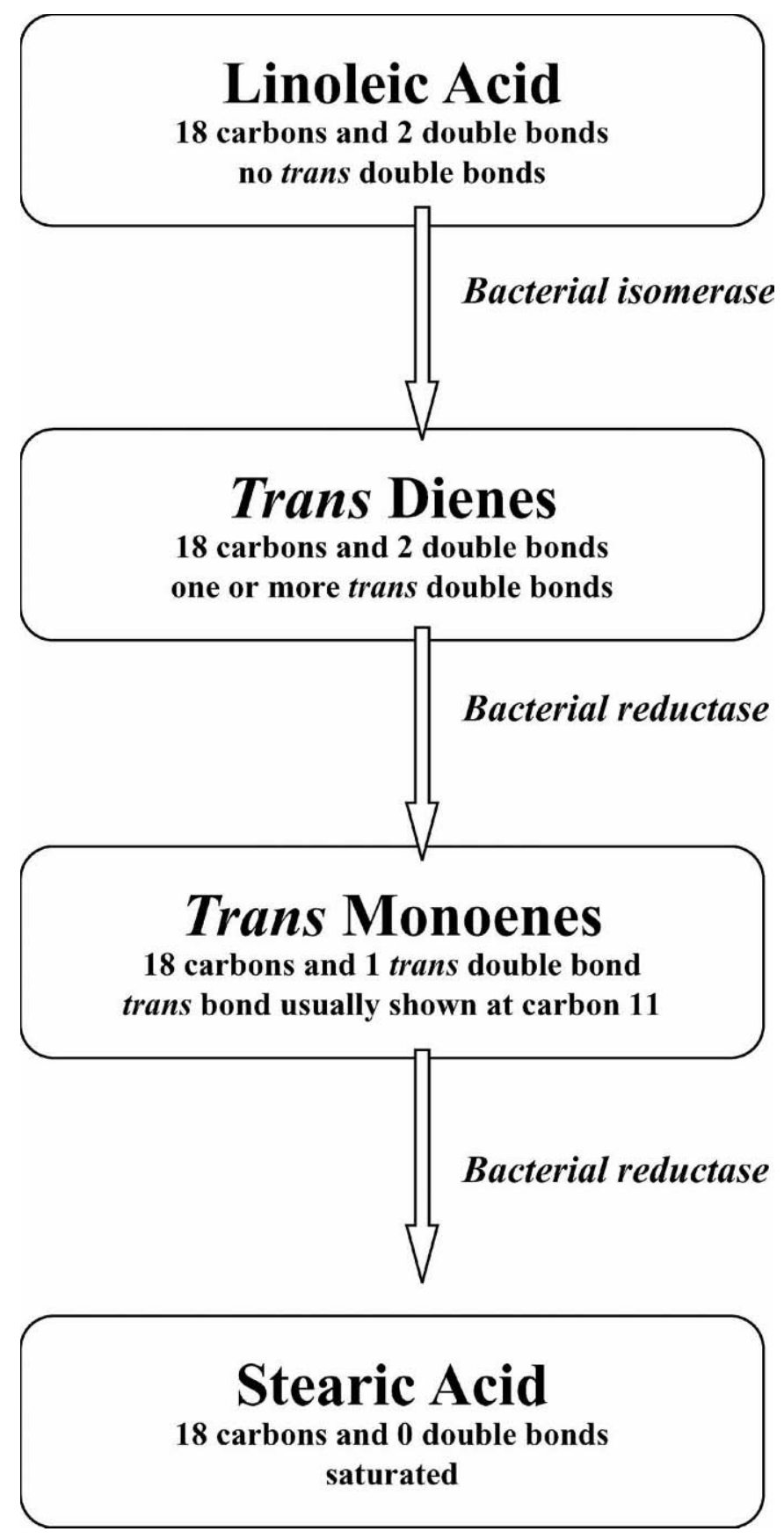

Figure 1. Major steps in the biohydrogenation of linoleic acid by ruminal microorganisms. Depending on conditions in the rumen, various proportions of stearic acid and trans intermediates are produced from linoleic acid. The trans diene intermediates usually include various conjugated isomers or conjugated linoleic acid.

Feeding rumen-protected fats increased the upper range of linoleic acid concentration to about 6.5\%.

One of the proposed rumen-protected fat sources that continues to be studied extensively is oilseeds. Oilseeds were shown in some studies to provide protection from biohydrogenation due to the nature of their hard outer seed coats, although the protection is probably best described as limited and inconsistent. Oilseeds are commonly processed (ground, extruded, pelleted) to enhance their handling, intake, or digestibility, which can significantly reduce their resistance to biohydrogenation.

Calcium salts of fatty acids also were examined for possible protection from biohydrogenation. They were originally developed at The Ohio State University by Don Palmquist and coworkers as a means to avoid digestibility problems when feeding high amounts of fat to dairy cattle. Key studies done at The Ohio State University and The University of Illinois in the mid1990s revealed some ability of unsaturated fatty acids in calcium salts of palm oil to resist biohydrogenation. Although the degree that calcium salts resist biohydrogenation is still under scrutiny, several commercial products are available using calcium salts to enhance the absorption of unsaturated fatty acids.

Amides of unsaturated fatty acids also were developed at Clemson University by Tom Jenkins in the early 1990 s as a way to enhance unsaturated fatty acids in milk. Studies done at Clemson University showed variable protection of amides from biohydrogenation depending on the specific fatty acid and amide linkage. Oleamide fed to lactating cows was able to substantially enhance oleic acid concentration in milk, but the same amide bond linkage with polyunsaturated fatty acids was less effective.

The scientific advances the last $25 \mathrm{yr}$ in elucidating and regulating the pathway of fatty acid biohydrogenation by ruminal microorganisms played an important role in achieving the present day successes in nutritional manipulation of milk composition. Work in this area was fueled by major discoveries showing physiological and health benefits of trans fatty acid intermediates that arise from the pathways of biohydrogenation, such as trans fatty acids and milk fat depression.

Another significant finding bringing a great deal of attention to biohydrogenation intermediates in milk fat was the discovery that CLA had beneficial effects on human health, most notably cancer-fighting properties. It was the cis-9,trans-11 CLA isomer in particular that received the most attention for its anticarcinogenic properties, which was known to arise from the biohydrogenation of linoleic acid. The recent interest in enhancing biohydrogenation intermediates in milk propagated research to determine the origin and possible enhancement of beneficial fatty acid isomers produced in the rumen. A number of studies used modern techniques of gas chromatography combined with mass spectroscopy to identify a multitude of positional and geometric trans isomers produced in ruminal contents from lipid 


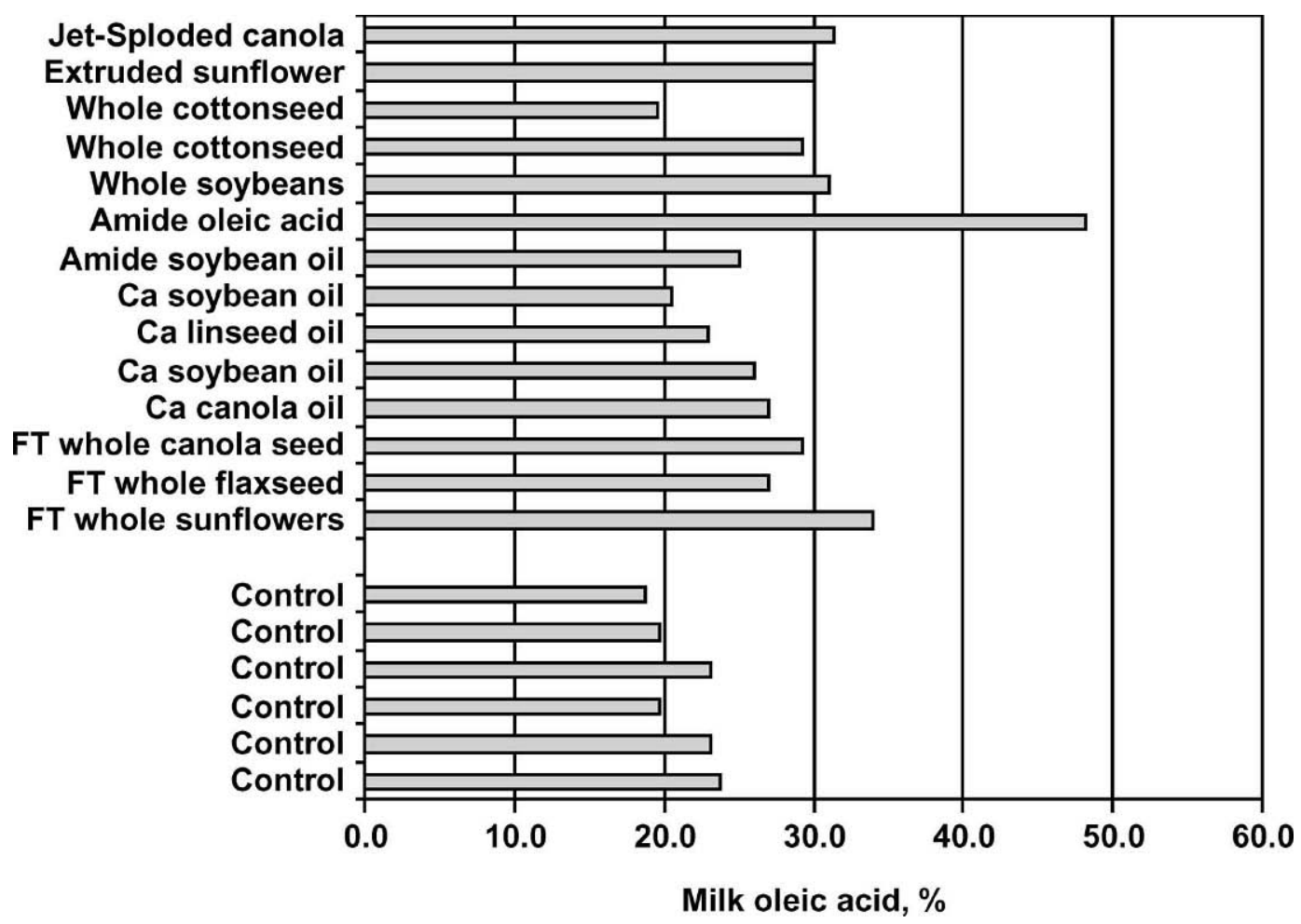

Figure 2. Samples of data from published studies showing the extent that oleic acid concentration in milk fat varies when lactating cows are fed control diets with no added fat or diets containing various sources of rumen-protected fat. Rumen-protected fat sources included whole oilseeds, amides of fatty acids, calcium (Ca) salts of fatty acids, and formaldehyde-treated (FT) fats.

biohydrogenation. More than 10 positional isomers of trans monoene fatty acids and a dozen or more CLA isomers have been identified in intestinal contents of ruminants in recent studies.

The discovery of a multitude of trans fatty acid isomers including CLA in the rumen of cattle confirmed the incompleteness of the pathways of biohydrogenation, which accounted for only a few of the trans isomers actually known to exist. Several advances followed that shed light on the origin of these trans intermediates. One of these was the proposal by Griinari and Bauman at Cornell University that a trans-10 double bond intermediate was formed from the biohydrogenation of linoleic and linolenic acids, followed by later work at Cornell University by Kim and Russell isolating a bacterium from ruminal contents that was capable of producing a trans-10,cis-12 CLA. At the same time, Mosley and Jenkins at Clemson University reported the conversion of labeled carbons from oleic acid to trans fatty acids by mixed ruminal microorganisms, including the formation of a trans-10 isomer.

Fatty Acid Use by the Mammary Gland. Many of the advances in nutritional manipulation of milk fat content were made possible by enhancing our basic understanding of the principles of nutrient uptake and use by the mammary gland. Many of the advances the last $25 \mathrm{yr}$ were focused on characterizing the regulatory steps in fatty acid synthesis and desaturation. Desaturase activity in the mammary secretory cell converts stearic acid arising from ruminal biohydrogenation to oleic acid that is secreted in milk. Thus, studies have been directed at enhancing activity of the $\Delta^{9}$-desaturase to increase oleic acid at the expense of saturated fatty acids in milk.

An important discovery within the last few years was the observation that the $\Delta^{9}$-desaturase was the predominant source of the cis-9,trans-11 CLA isomer in milk, which has a number of benefits to human health (including anticarcinogenic properties). Trans-11 arising from biohydrogenation in the rumen is transferred to the mammary tissue and desaturated to $c i s-9$,trans -11 CLA via the $\Delta^{9}$-desaturase. This has shifted attention to manipulating ruminal biohydrogenation to enhance the yield of the trans-11 isomer.

Research at the cellular and molecular level promises to unveil even more opportunities for regulating fatty acid synthesis and desaturation in mammary tissue. Some recent areas of investigation include CLA effects on the synthesis and abundance of mRNA for key mammary enzymes involved in de novo fatty acid synthesis, 


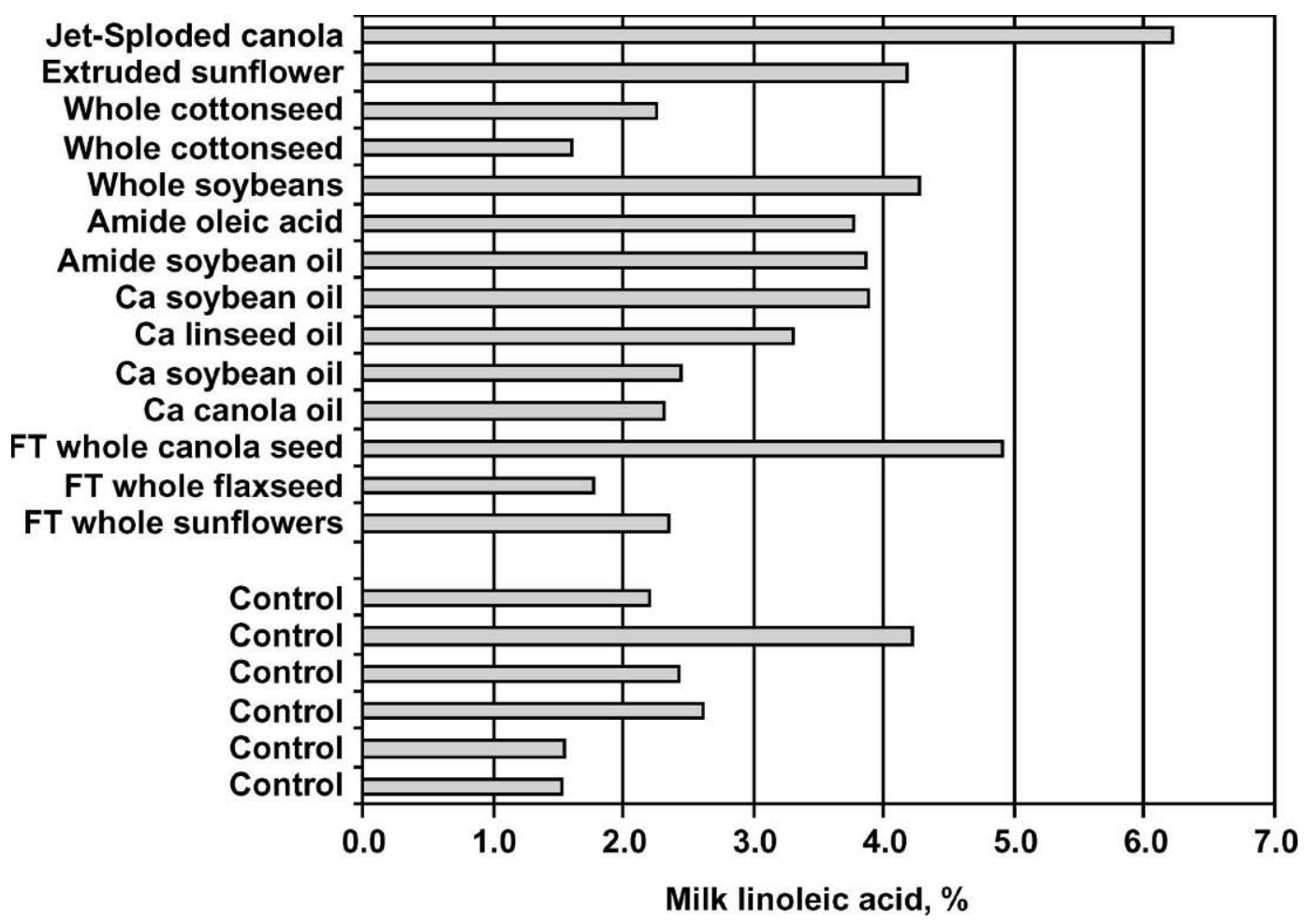

Figure 3. Samples of data from published studies showing the extent that linoleic acid concentration in milk fat varies when lactating cows are fed control diets with no added fat or diets containing various sources of rumen-protected fat. Rumen-protected fat sources included whole oilseeds, amides of fatty acids, calcium $(\mathrm{Ca})$ salts of fatty acids, and formaldehyde-treated (FT) fats.

and the effects of CLA isomers on the peroxisome proliferator-activated receptor and sterol regulatory element-binding protein family of nuclear transcription factors.

\section{MILK PROTEIN}

\section{Target}

The nitrogen fractions of milk can be broadly divided into 3 categories; casein, whey, and NPN. Casein comprises the majority of the nitrogen in milk (about 78\%), with lesser amounts of whey N (17\%) and NPN (5\%). In cheese making, curd structure, curd firmness, and cheese yield are directly related to casein content. The nutritional factors receiving the most attention the last $25 \mathrm{yr}$ for their influence on milk protein content were forage-to-concentrate ratio, the amount and source of dietary protein, and the amount and source of dietary fat.

As pointed out in the excellent review on manipulating the nitrogen composition of milk by DePeters and Cant (1992), it is important to distinguish between responses that affect protein content (percentage in milk) vs. those affecting protein yield ( $\mathrm{kg}$ of protein/d). It often happens that dietary changes having positive impacts on milk and protein yields cause negative effects on protein content. The goal in most instances is to increase protein content while maintaining or increasing milk yields.

\section{Forage-to-Concentrate Ratio}

In most cases, reducing the proportion of forage in the diet of a cow increases both protein content and yield. Milk protein content can be increased by 0.4 percentage units or more if forage proportion in the diet is reduced to $10 \%$ or less of the diet DM. Because a minimum concentration of forage is needed in typical dairy diets (generally at least $40 \%$ ) to avoid digestive and metabolic disturbances, reducing the forage-to-concentrate ratio has not been a practical method of consistently enhancing milk protein content. Another issue has been to determine if forage is the direct cause of milk protein depression, or if it is an indirect effect of decreasing energy intake. Limited research on this question the last $25 \mathrm{yr}$ points to a greater role for energy intake, with fiber content of the ration having little direct influence on milk protein content.

Rapidly fermentable dietary carbohydrate has been associated with milk protein content through meta- 


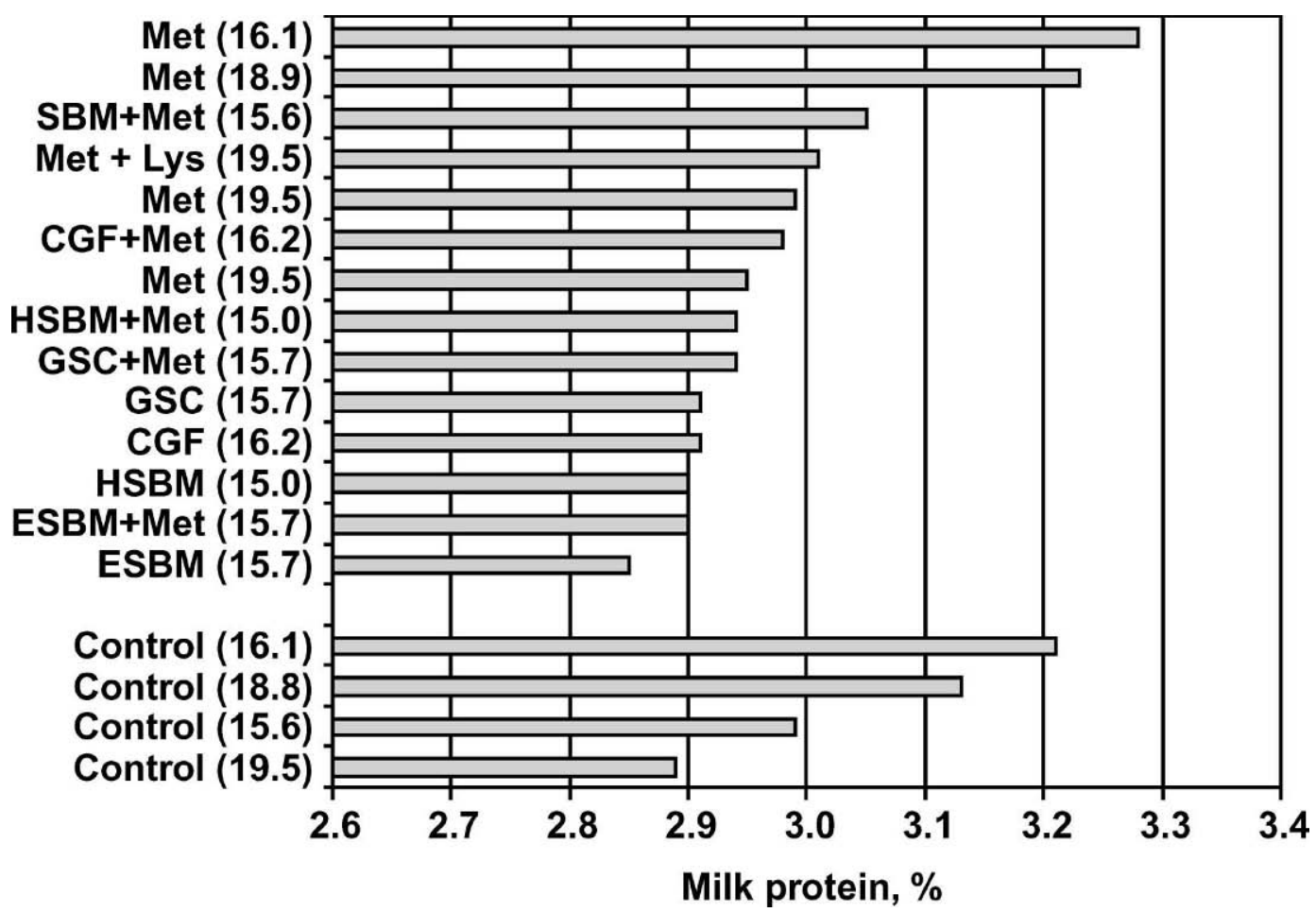

Figure 4. Samples of data from published studies showing the extent that milk protein percentage varies with amount and type of dietary protein. Diet protein percentage is shown in parenthesis following source of protein, which includes the amino acids methionine and lysine, soybean meal (SBM), corn gluten feed (CGF), heated soybean meal (HSBM), ground shelled corn (GSC), and extended soybean meal (ESBM)

analysis. Tying the fermentation of starch to propionate production in the rumen led to a series of experiments in which the effects of insulin were evaluated on milk protein content and yield. The hyperinsulinemic-euglycemic clamp technique was used to examine raised insulin concentrations without the confounding effects of hypoglycemia. Results demonstrated a modest increase in milk protein unless casein was infused abomasally. When combined, insulin and casein produced substantial increases in milk protein content (10\%) and yield (28\%). These results may explain how changes in the forage-to-concentrate ratio regulate milk protein production. When rapidly fermentable carbohydrate is fed, greater production of propionate and microbial protein is produced leading to signals in the cow's body to produce more milk and milk protein.

\section{Amount and Source of Protein}

Unlike forage-to-concentrate ratio, the effects of amount and source of protein in the diet on milk protein content have been extensively investigated. However, it soon became clear that dramatic changes in either amount or source of protein caused only modest changes in the protein content of milk. The data in Figure 4 show a spread of milk protein from 2.85 to $3.27 \%$ as protein content in the diet varied from 15.0 to $19.5 \%$ and included a wide variety of protein sources, including rumen-protected amino acids. As pointed out by Roy Emery at Michigan State University in his 1978 review on feeding for increased milk protein, protein content of milk increases only about 0.02 percentage units for each 1 percentage unit increase in dietary protein.

A low transfer efficiency (25 to 30\%) of dietary protein to milk is a major factor accounting for the inability of diet to markedly alter milk protein content. An excellent review of the protein transfer limitations from diet to milk was given by Bequette, Backwell, and Crompton located at the Rowett Research Institute and the University of Reading (United Kingdom). Their review discusses that adequate amino acids are delivered to mammary tissue, but that a key factor for the low rates of transfer relates to poor capture of the amino acids by the mammary gland. Blood flow through the mammary gland is implicated as a key cause of this poor capture, which is part of the overall process for the coordinated timing of nutrient delivery to the mammary gland. Contrary to this point, studies in cows undergoing a hyperinsulinemic-euglycemic clamp show that both mammary blood flow and amino acid extraction can adjust 
leading to enhanced milk protein production. This suggests that the mammary gland has the capacity to alter the uptake of substrates from the arterial supply in response to changes in arterial amino acid concentrations, mammary blood flow, and metabolic activity to improve milk protein production.

\section{Amount and Source of Fat}

As fat supplements were being explored as energy sources for dairy cows, it soon became apparent that feeding additional fat was often accompanied by a decline in milk protein content. As a result, feeding fat had to be limited in markets where milk pricing gave an incentive to protein content. On average, protein content in milk declined 0.03 percentage units for each $100 \mathrm{~g}$ of supplemental fat intake, or about 0.1 to 0.3 percentage units for most typical levels of fat feeding. When fat supplementation reduced milk protein content, the casein fraction declined the most. Fat effects on the whey fraction were inconsistent and NPN generally increased. Because fat supplements increased milk yield when properly fed, total daily production of milk protein remained the same or even increased when fat was fed, despite the decline in protein content.

Several important studies were done in the last 25 yr to elucidate the mechanism whereby fat supplements cause this dilution effect, i.e., a greater increase in milk yield than protein yield. One such proposal was by Casper and Schingoethe at the University of South Dakota. They proposed that elevated blood fatty acids from the fat supplement decreased the release of somatotropin, which reduced mammary extraction of amino acids. Work done by Cant, DePeters, and Baldwin at the University of California led to an alternative proposal. In a 1991 study, they showed that infusing casein into the abomasum of lactating cows fed $4 \%$ yellow grease increased arterial amino acid concentrations but failed to prevent the milk protein depression. In a later 1993 study, they observed a 7\% drop in mammary blood flow when cows were fed fat, thus preventing increased removal of critical amino acids as milk synthesis increased. The same researchers proposed that fat supplements reduced milk protein concentration by reducing blood flow through the mammary gland causing reduced extraction of blood amino acids. Milk volume is increased in their explanation by the higher fatty acids inhibiting mammary de novo fat synthesis, causing a sparing of acetate for oxidation and more glucose available for lactose and milk synthesis.

\section{MILK LACTOSE}

As stated earlier, few studies have detected any significant change in lactose content of milk in cows fed diets in the normal range. Studies using mice have evaluated the impact of low lactose content on milk production. Using gene knockouts of $\alpha$-lactalbumin, these studies have determined that lactose synthesis requires $\alpha$-lactalbumin. This may not be advantageous to the dairy industry, as the milk produced was too viscous to be removed by the nursing pups. Therefore, it is likely that postharvest technology will be required to reduce lactose content of milk.

\section{FUTURE DIRECTIONS}

To the extent that milk pricing is linked to milk components, producers will continue to exploit nutrition of the cow as a means to modify milk composition for maximum economic return. As more coverage of the bovine genome becomes publicly available, opportunities will be explored to genetically manipulate or develop lines of cows that produce milk with a specific composition. Nutrition will remain an integral part of expressing this modified genetic potential. The greatest opportunities on the horizon for manipulating milk composition will be directed at using milk for delivery of nutraceuticals to enhance human health and to combat clinical diseases such as obesity, lactose intolerance, or osteoporosis. The fatty acid profile of milk will continue to receive attention in these areas, as it is a reservoir for many of the unique (and as yet unknown) trans isomers of ruminal origin having a wide range of physiological responses. Enhancing specific proteins in milk to enhance human health will also be important, but because milk protein composition is less responsive to diet than fat, postharvest manipulation by processors and food scientists will play a major role.

\section{REFERENCES}

Bauman, D. E., and J. M. Griinari. 2003. Nutritional regulation of milk fat synthesis. Annu. Rev. Nutr. 23:203-227.

Bequette, B. J., F. R. C. Backwell, and L. A. Crompton. 1998. Current concepts of amino acid and protein metabolism in the mammary gland of the lactating ruminant. J. Dairy Sci. 81:2540-2559.

Berner, L. A. 1993. Roundtable discussion on milkfat, dairy foods, and coronary heart disease risk. J. Nutr. 123:1175-1184.

Cant, J. P., E. J. DePeters, and R. L. Baldwin. 1991. Effects of dietary fat and postruminal casein administration on milk composition of lactating dairy cows. J. Dairy Sci. 74:211-219.

Cant, J. P., E. J. DePeters, and R. L. Baldwin. 1993. Mammary amino acid utilization in dairy cows fed fat and its relationship to milk protein depression. J. Dairy Sci. 76:762-774.

Casper, D. P., and D. J. Schingoethe. 1989. Model to describe and alleviate milk protein depression in early lactation cows fed a high fat diet. J. Dairy Sci. 72:3327-3335.

DePeters, E. J., and J. P. Cant. 1992. Nutritional factors influencing the nitrogen composition of bovine milk: A review. J. Dairy Sci. 75:2043-2070.

Dixon, L. B., and N. D. Ernst. 2001. Choose a diet that is low in saturated fat and cholesterol and moderate in total fat: Subtle changes to a familiar message. J. Nutr. 131:510S-526S. 
Emery, R. S. 1978. Feeding for increased milk protein. J. Dairy Sci. 61:825-828.

Jenkins, T. C. 1993. Lipid metabolism in the rumen. J. Dairy Sci. 76:3851-3863.

Jenkins, T. C. 1998. Fatty acid composition of milk from Holstein cows fed oleamide or high-oleic canola oil. J. Dairy Sci. 81:794-800.

Mansbridge, R. J., and J. S. Blake. 1997. Nutritional factors affecting the fatty acid composition of bovine milk. Br. J. Nutr. 78(Suppl. 1):S37-S47.
Putnam, J., and J. Allshouse. 2003. Trends in U.S. per capita consumption of dairy products, 1909 to 2001. Amber Waves, The Economics of Food, Farming, Natural Resources, and Rural America, USDA Economic Research Service, Washington, DC.

United Kingdom Department of Health. 1994. Nutritional Aspects of Cardiovascular Disease. Report on Health and Social Subjects (no. 46). H. M. Stationery Office, London, UK.

USDA-ARS. 2004. USDA National Nutrient Database for Standard Reference, Release 18. USDA Agricultural Research Service, USDA Nutrient Data Laboratory, Washington, DC. 